\section{Caging Single Avocado Trees with a Beehive Does Not Guarantee Exclusive Formation of Selfed Progeny}

\author{
C. Degani, E. Lahav, and R. El-Batsri \\ Institute of Horticulture, Agricultural Research Organization, The Volcani \\ Center, Bet-Dagan 50250, Israel
}

\author{
S. Gazit \\ The Institute of Plant Sciences and Genetics in Agriculture, The Hebrew \\ University of Jerusalem, Rehovot 76100, Israel
}

Additional index words. Persea americana, isozyme analysis, pollination

\begin{abstract}
Single trees of several avocado (Persea americana Mill.) cultivars were caged with a beehive for the production of selfed progeny. Isozyme analysis was used to identify undesirable outcrosses in the planted progenies. Outcrossing rates were found to be highly variable, ranging from 0 to 0.86 . Short accidental breaches in the net's integrity were suspected to be the main cause for the haphazard appearance of hybrids. Indeed, when 'Tova', which consistently had progenies with a high rate of hybrids (averaging 0.58 ) was caged very meticulously, outcrossing rate was consistently low, averaging only 0.07 . Apparently, short periods of accidental exposure to open pollination can result in a high percentage of outcrossed progeny, due to the higher survival rate of outcrossed fruitlets compared to selfed ones. The residual low outcrossing rate found with meticulous caging probably occurred through the penetration of floating foreign pollen from adjacent trees. Thus, the production of pure selfed progeny in avocado requires meticulous caging and the absence of foreign cultivars around the caged trees. In general, the fact that net caging was not fully effective in excluding foreign pollen should encourage the performance of parentage analysis to confirm the purity of progenies produced in net cages.
\end{abstract}

Effective pollination of subtropical avocado (Persea americana Mill.) is carried out by the transfer of pollen from a dehisced male stage flower to the receptive stigma of a female stage flower. Overlap between female and male opening occurs most of the time under subtropical climates; thus enabling extensive close-pollination within the tree. In most subtropical countries pollination is performed almost exclusively by large insects, especially the honeybee (Apis mellifera L.) and large flies. Caging subtropical avocado without pollinators usually results in no, or only a few fruit (Gazit and Degani, 2002).

The production of selfed progeny is important for breeding and genetic analysis. In the Israeli avocado breeding program, largescale caging was used for this purpose. In the following report, we present the results of a parentage analysis which revealed an unexpectedly high rate of hybrids in many of these "selfed" progenies, and describe the work done to elucidate the reasons for this occurrence.

\section{Materials and Methods}

Single avocado trees of several subtropical cultivars (Ettinger, Hass, Horshim, Irving, Nabal, Rincon, Tova and Wurtz) were caged with a beehive from 1974 to 1987 , in order to

Received for publication 22 Oct. 2001. Accepted for publication 7 Mar. 2003. Contribution from the Agricultural Research Organization, The Volcani Center, Bet Dagan, Israel, no. 07, 2003 series. produce selfed progeny. Single 'Tova' trees were also caged from 1989 to 1992, with greater precautions taken to maintain cage integrity. A 15-mesh net was used to prevent the entrance of avocado pollinators (honeybees and flies) carrying foreign pollen. Trees were caged just prior to the onset of flowering until the end of the bloom. Trees of other cultivars usually surrounded the caged trees; the distance between their foliage and that of the caged tree was often $<1 \mathrm{~m}$.

The progenies originating on the caged trees in 1974 to 1987 were planted in breeding plots. Several years later, isozyme analysis was performed to determine whether undesirable hybrids had been produced. Leaves were sampled from all seedling trees in each progeny ( 25 to 122 seedlings per progeny). From 1989 to 1992, isozyme analysis was performed on the cotyledons (Torres, 1984) of all the caged fruit.

Isozyme analysis was performed (Degani and Gazit, 1984; Degani et al., 1997) for leucine aminopeptidase (LAP; EC 3.4.11.1), phosphoglucomutase (PGM; EC 2.7.5.1), malate dehydrogenase (MDH; EC 1.1.1.37), triosephosphate isomerase (TPI; EC 5.3.1.1) and aspartate aminotransferase (AAT; EC 2.6.1.1). Outcrossing rate in each cultivar was determined by using the homozygous loci Aat-1,Lap-2, Mdh-1, Pgm-1 and Tpi-1. The homozygous genotypes of the caged cultivars were: Lap-2 FF ('Anaheim', 'Hass', 'Horshim', 'Irving', 'Nabal', Rincon', 'Tova', and 'Wurtz'); Mdh-I SS ('Anaheim', 'Ettinger', 'Hass', 'Horshim', 'Nabal', 'Rincon', and
'Wurtz'); Pgm-1 FF ('Anaheim', 'Horshim', 'Irving', 'Rincon', and 'Tova'); and Tpi-I SS ('Anaheim', 'Hass', 'Horshim', 'Nabal', and 'Wurtz'). For Aat-1, the homozygous genotypes were $F F$ ('Ettinger') or SS ('Anaheim'). Multilocus estimates of outcrossing rate were determined as described previously (Degani et al., 1997; Shaw et al., 1981).

\section{Results and Discussion}

Outcrossing rates for progenies produced from 1974 to 1987 were highly variable, ranging from 0 to 0.86 . No outcrossed progeny were found on 'Ettinger', and low outcrossing rates were found on 'Nabal' $(0.08)$ and 'Anaheim' (0.09). In contrast, the outcrossing rates were unexpectedly high for the cultivars Wurtz, Tova, Irving, Horshim, Rincon, and Hass: $0.55,0.58,0.65,0.67,0.78$, and 0.86 , respectively.

The probability of identifying outcrosses depended on the number of unlinked isozyme loci tested. Thus, the use of two isozyme loci for 'Ettinger', 'Irving', and 'Tova', three for 'Hass', 'Nabal', 'Rincon', and 'Wurtz', four for 'Horshim' and five for 'Anaheim', enabled the identification of $70 \%, 87.5 \%, 92.75 \%$, and $96.78 \%$ of the outcrosses, respectively. Therefore, the presented values for outcrossing rates are underestimates, especially when only two or three isozyme loci were used.

We attributed these unanticipated results to small accidental breaches in the cages' integrity. On several occasions, cages were overturned by storms and usually reinstalled the next day. In addition, tears were sometimes detected and immediately repaired. On these occasions, pollinators carrying foreign pollen were not prevented from visiting the flowers. As no written records of these occurrences were available at the time these high outcrossing rates were detected, we assumed that the difference among cultivars was accidental, caused by the haphazard breaches in the cages' integrity.

To investigate this assumption, single trees of 'Tova', a cultivar with consistently high outcrossing rates (0.49 to 0.69$)$ (Table 1), were caged during the years 1989 to 1992. Environmental conditions were the same for the two series of caging. One of the experimental trees was caged in 1987 (first series)

Table 1. Outcrossing rate in the progeny of single 'Tova' trees caged with a beehive.

\begin{tabular}{lcc}
\hline Year & $\begin{array}{c}\text { Offspring } \\
\text { assayed (no.) }\end{array}$ & $\begin{array}{c}\text { Outcrossing } \\
\text { rate }^{\mathrm{z}}\end{array}$ \\
\hline 1974 & 70 & $0.69 \pm 0.08$ \\
1975 & 53 & $0.58 \pm 0.09$ \\
1976 & 99 & $0.62 \pm 0.07$ \\
1987 & 112 & $0.49 \pm 0.06$ \\
& $\mathbf{M e a n}^{\mathrm{z}}$ & $\mathbf{0 . 5 8} \pm \mathbf{0 . 0 4}$ \\
1989 & $490^{\mathrm{y}}$ & $0.09 \pm 0.02$ \\
1990 & 140 & $0.06 \pm 0.02$ \\
1991 & 130 & $0.03 \pm 0.02$ \\
1992 & 120 & $0.14 \pm 0.04$ \\
& Mean $^{\text {z }}$ & $\mathbf{0 . 0 7} \pm \mathbf{0 . 0 1}$ \\
\hline
\end{tabular}

${ }^{2}$ Weighted means by the inverse of the variances \pm standard error

yFruits were collected from two 'Tova' caged trees. 
and in 1989 and 1990 (second series). However in the second series, much greater precautions were taken to maintain cage integrity.

During the 4 years that the cage's integrity was strictly maintained, outcrossing rates in 'Tova' progeny were consistently much lower than in the prior 4 years, when integrity was not so well maintained, 0.07 compared to 0.58 (Table 1). These results support the conclusion that breaches in the cages' integrity were responsible for the high outcrossing rates in 1974 to 1976 and 1987. Therefore, absolute enclosure of trees throughout their flowering is crucial for producing selfed progeny.

The fact that the accidental exposure to cross-pollination was relatively short, 1 or $2 \mathrm{~d}$ out of $\approx 2$ months of bloom, led us to the erroneous assumption that the percentage of outcrossed progeny would also be very small. We did not take into account that with several thousand fresh flowers opening daily on a mid-size avocado tree, a 1-d breach might enable the initial set of hundreds of fruitlets by cross-pollination. Previous research has indicated that outcrossed fruitlets have a greater survival rate than selfed ones, and as a result, a minuscule set of outcrossed fruitlets can be transformed into a high percentage of mature outcrossed fruit (Degani et al., 1989, 1997). Hence, under environmental conditions that are favorable for pollination and the fertilization process, even a few hours' exposure to foraging bees could result in several tens of hybrid fruit per tree.

Davenportet al. (1994) concluded that wind is the primary mediator of pollen transfer for tropical avocado cultivars in south Florida. However, under subtropical conditions, insect pollinators are essential for effective pollination in avocado (Gazit and Degani, 2002). Indeed, 'Tova' trees caged in Israel without pollinators bore only a few fruit (Gazit, 1977). Also in Israel, Katz (1995) found a low density of floating avocado pollen near avocado trees. The low outcrossing rate $(0.07)$ found when 'Tova' trees were meticulously caged (Table 1) was probably due to such airborne foreign pollen. Hence, to ensure the production of pure selfed progeny in avocado, meticulous caging may not suffice: all trees in the vicinity should also be of the same cultivar.

\section{Literature Cited}

Davenport, T.L., P. Parnitzki, S. Fricke, and M.S. Hughes. 1994. Evidence and significance of selfpollination of avocados in Florida. J. Amer. Soc.
Hort. Sci. 119:1200-1207.

Degani, C., R. El-Batsri, and S. Gazit. 1997. Outcrossing rate, yield and selective fruit abscission in 'Ettinger' and 'Ardith' avocado plots. J. Amer. Soc. Hort. Sci. 122:813-817.

Degani, C. and S. Gazit. 1984. Selfed and crossed proportion of avocado progenies produced by caged pairs of complementary cultivars. HortScience 19:258-260.

Degani, C., A. Goldring, and S. Gazit. 1989. Pollen parent effect on outcrossing rate in 'Hass' and 'Fuerte' avocado plots during fruit development. J. Amer. Soc. Hort. Sci. 114:106-111.

Gazit, S. 1977. Pollination and fruit set of avocado, p. 88-92. In: J.W. Sauls, R.F. Phillips, and L.K. Jackson (eds.). Proc. ${ }^{\text {st }}$ Intl. Trop. Short Course, the Avocado. Univ. of Florida, Gainesville.

Gazit, S. and C. Degani. 2002. Reproductive biology, p. 101-133. In: A.W. Whiley, B. Schaffer, and B.N. Wolstenholme (eds.). The avocado. CAB International, Wallingford, U.K.

Katz, E. 1995. Avocado productivity: Pollination, pollenizers, fruit set and abscission (in Hebrew). M.Sc. Thesis, Faculty of Agr. The Hebrew Univ. of Jerusalem, Rehovot, Israel.

Shaw, D.V., A.L. Kahler, and R.W. Allard. 1981. A multilocus estimator of mating system parameters in plant populations. Proc. Natl. Acad. Sci. 78:1298-1302.

Torres, A.M. 1984. Isozymes from avocado cotyledons. J. Hered. 75:300-302. 